\title{
Fluorescence optical imaging for treatment monitoring in patients with early and active rheumatoid arthritis in a 1-year follow-up period
}

Anne-Marie Glimm, Lisa Ines Sprenger', Ida Kristin Haugen², Ulrich Mansmann³, Sandra Hermann, Thomas Häupl', Paula Hoff ${ }^{1}$, Gerd-Rüdiger Burmester ${ }^{1}$, Marina Backhaus ${ }^{1,4}$, Lien Le ${ }^{3}$ and Sarah Ohrndorf ${ }^{*}$

\begin{abstract}
Background: Fluorescence optical imaging (FOI) enables visualization of inflammation in the hands in rheumatic joint diseases with currently a lack of long-term follow-up studies.

Objective: To investigate FOl for treatment monitoring in a homogenous cohort of patients with early (disease duration $<2$ years) and active (DAS28 > 3.2) RA over a period of 12 months.

Methods: Thirty-five RA patients (24 (68.6\%) females, mean age 53.3 years (SD 13.6)) were investigated clinically by DAS28, tender joint count (TJC) and swollen joint count (SJC) and by FOI in phases 1-3 and PrimaVistaMode (PVM) before therapy change and after 12 months. The FOI activity score (FOIAS) was calculated based on individual joint scores from 0 to 3 in 30 joints per patient, adding up to a sum score (0-90).

Results: We found a statistically significant reduction of FOIAS in phase 1 from baseline (median 5.0, IQR 24.96) to follow-up (median 1.0, IQR 4.0) in all patients ( $p=0.0045$ ), both in responders and non-responders according to EULAR response criteria by DAS28. Statistically significant reductions over 12 months were found for median DAS28(ESR) 5.61 to 3.31, TJC 7.0 to 1.0, and SJC 5.0 to 1.0 (each $p<0.001$ ). No statistically significant correlations were detected between the FOIAS change in phase 1 and DAS28(ESR), TJC, or SJC. Correlations between the other phases and clinical outcomes were weak to moderate.

Conclusion: Reduced early enhancement in FOI phase 1 can be observed in clinically responding and nonresponding early RA patients under treatment. Regarding potential marker performance, $\mathrm{FOI}$ probably shows a reduction of inflammation more objectively.
\end{abstract}

Keywords: Arthritis, rheumatoid, Fluorescence, Ultrasonography, Follow-up studies

\section{Background}

To monitor therapeutic response in patients with rheumatoid arthritis (RA), clinical disease activity scores such as DAS28 are applied [1]. Besides, more sensitive and objective imaging modalities are recommended in the clinical management of RA [2]. Magnetic resonance imaging (MRI) and musculoskeletal ultrasound (US) are both widely used in clinical practice and research within the

\footnotetext{
* Correspondence: sarah.ohrndorf@charite.de

${ }^{1}$ Department of Rheumatology and Clinical Immunology,

Charité-Universitätsmedizin Berlin, Charitéplatz 1, 10117 Berlin, Germany

Full list of author information is available at the end of the article
}

field of RA [3-8]. MRI-detected pathologies such as synovitis and tenosynovitis are highly responsive to antirheumatic treatment [9-11]. However, MRI has the disadvantage of high costs, time exposure, and occasional contraindications (e.g., pacemaker and claustrophobia) [12]. In several studies, US-detected synovitis and tenosynovitis have also been shown to be sensitive to change under therapy, especially in Power Doppler mode (PDUS) [13-16] reflecting disease activity. US is a cost-effective, widespread method that is risk-free for patients, is indefinitely repeatable, and involves less inconvenience than MRI. Drawbacks may be the dependency on the examiner 
[17] and the inability to pairwise compare baseline and follow-up images immediately while investigating unless all images are saved for analysis later on; however, US images are usually saved as "still images" (lost of dynamic approach).

In search of an imaging method for the optimal detection of disease activity, new procedures are developed and investigated. Since 2009, the fluorescence optical imaging (FOI) "Xiralite" (Xiralite GmbH, Berlin, Germany) has been shown to detect inflammation in preclinical studies $[18,19]$ as well as in humans $[20-26]$ in the joint regions of both hands. The basis of the Xiralite method is the demonstration of an impaired microcirculation caused by the inflammatory process of arthritis. Here, the enhancement of an intravenously applied dye indocyanine green (ICG) is evaluated. FOI is a non-ionizing technique that examines both hands in one session of $6 \mathrm{~min}$. Besides, the examination itself can be performed by clinical assistants. Impediments in the sense of resulting contraindications are an impaired liver function, since the applied dye is primarily excreted biliarily [27]. Furthermore, an allergic reaction to the ICG solution can occur [28]. However, the overall risk of ICG to the patient is low [29].

Previous studies have demonstrated good agreements between FOI, clinical assessment, MRI, and US [21] as well as a moderate und substantial reliability for the scoring of FOI images [22]. Additionally, FOI may also detect subclinical inflammation [25]. Only one study has evaluated the responsiveness of FOI, so far. Meier et al. found a reduction in the signal intensity during therapy response in a group of patients with forms of different arthritis who were examined by a computer-based evaluation of FOI and MRI; however, the observed group was heterogeneous and only investigated over a time period of 6 months [30].

The aim of the present study was the investigation of FOI's ability to reflect treatment response in a homogenous cohort of patients with early and active RA over a period of 12 months. Besides, we aimed for exploration of its correlations with clinical outcomes such as DAS28. The correlation with US as a common imaging modality in daily rheumatological practice was set as a secondary outcome.

\section{Methods}

This study is a subproject (No. 7) of the Arthromark project as a national research network in Germany funded by the Federal Ministry of Education and Research (BMBF). The main goal of the several Arthromark subprojects is the identification of new biomarkers including the application and assessment of new and modern imaging techniques in terms of making a diagnosis and follow-up examinations in patients with RA, psoriasis arthritis, and spondyloarthritis [31].
In this subproject, we included 42 patients with early (disease duration $<24$ months) and active (DAS28 > 3.2) RA, who started therapy with conventional synthetic diseasemodifying antirheumatic drugs (csDMARDs) or escalated therapy with initiation of biologic therapy (bDMARD) after failure of conventional therapy. Over a period of 1 year, patients were examined clinically and by US (for further description of additional US, see Additional file 1) five times (baseline, after 6 weeks, and 3, 6, and 12 months). FOI was performed at baseline and after 12 months in 35 patients who were included in these analyses (in seven patients, the 12-month visit was not performed).

\section{Clinical and laboratory examination}

A clinical assessment of tender (28 tender joint count (TJC)) and swollen joints (28 swollen joint count (SJC)) was performed. Patients self-reported their evaluation of the global disease activity and the current general joint pain (both on a visual analog scale (VAS) 0-100 mm). Clinical and laboratory examination was accomplished on the same day as the imaging (FOI; US) examinations. Usually, FOI was ordinarily performed after the US examination. The laboratory investigation included the assessment of erythrocyte sedimentation rate (ESR) and C-reactive protein (CRP). The rheumatoid factor (RF) and anti-citrullinated peptide antibodies (ACPA) were determined at inclusion.

The Disease Activity Score DAS28 was calculated based on the 28-TJC, 28-SJC, ESR or CRP, and patient's global VAS [1]. The calculation of the difference between DAS28 value at baseline or the prior visit and current value gave information of response to therapy after EULAR response criteria [32-34] (a definition is presented in Additional file 1: Table S1). Based on the EULAR response (Table S1), patients were assigned to a group of responders (DAS28(ESR) $\leq 3.2$ and improvement of >0.6) or non-responders (DAS28(ESR) > 3.2). This process was done to evaluate treatment monitoring by FOI.

\section{Fluorescence optical imaging (FOI)}

FOI (Xiralite ${ }^{\circ}$ System) was performed following a standardized procedure.

The examination term lasted $6 \mathrm{~min}$, recording one image per second and adding up to a cluster of 360 images $[21,22]$. A bolus of indocyanine green (ICG) as fluorescence optical dye with a dose of $0.1 \mathrm{mg} / \mathrm{kg}$ body weight was injected intravenously $10 \mathrm{~s}$ after the beginning of the examination $[21,22]$.

The attached software system enabled a visualization of invasion and distribution of ICG in the hands. An image sequence in the film modus and an automatically generated image in the PrimaVistaMode (PVM) were analyzed to evaluate the distribution and enhancement of ICG. For 
the film modus, three phases in position to the fingertips were defined regarding signal intensities depending on individual perfusion [22]. Phase 1 (p1) included the period between starting the investigation, application of the dye, and increased signal intensities in the fingertips [22], which means an increasing intensity of fluorescence signal. The time period of persisting high signal intensities as plateau in the fingertips was defined as phase 2 (p2) [22]. Investigators do identify this phase on red color signs of the enhancement in the fingertips. The time point without signal intensity meaning only yellow sparkles in the fingertips as a signal for clearance determined the beginning of phase 3 (p3) [22].

Enhancement of ICG can be graded by false-color illustration, which is identical between different scans, time points, and patients. It defines white enhancement as high intensities and concentration of ICG. Red, yellow, and green enhancement follows in a descending order of ICG concentration. For analyzing the joint activity by FOI, the evaluation at the joint level included a combination of size, shape, and color of the signal in a semiquantitative grading system (FOIAS; fluorescence optical imaging activity score): $0=$ no signal enhancement, green to yellow signals; $1=$ low signal intensity ( $\leq 25 \%$ of the joint area affected), yellow-red signals including red signals with yellow spots; $2=$ moderate signal intensity ( $>25 \%, \leq 50 \%$ of the joint area affected), strong red signals including red signals with white spots; $3=$ strong signal intensity ( $>50 \%$ of the joint area affected), white signals $[21,22]$. If there was a discrepancy between the intensity of the color and the size of the enhancement, the lower grade of the scoring system was assigned. In detail, enhancements with a discrepancy between two subsequent grades (1 and 2 or 2 and 3) were evaluated with the lower grade number. Differences of signal color and size between grades far apart (e.g., grades 1 and 3) were scored with the intermediate grade (e.g., grade 2).

The ICG distribution in the three phases (p1, p2, p3) and in PrimaVistaMode (PVM) was assessed for the joint regions of 30 joints per patient, including the bilateral wrist, metacarpophalangeal joints (MCP) $\mathrm{I}-\mathrm{V}$, proximal interphalangeal joints (PIP) II-V, distal interphalangeal joints (DIP) II-V, and interphalangeal joint of the thumb (IP) [21]. The scoring of color intensity, size, and shape of ICG enhancement was performed by an agreement-based consensus of two investigators (SO; LS).

We calculated the number of affected joints and sum scores (FOIAS; fluorescence optical imaging activity score) for each phase (0-90 scales). In addition, the sum scores of the left hand and the right hand were individually calculated.

\section{Statistical analyses}

Wilcoxon signed rank tests were done to compare clinical data (TJC, SJC, DAS28(ESR)) and FOIAS between two visits (baseline (V0) and 12 months (V12)). Furthermore, Mann-Whitney $U$ tests were performed to test for the statistical significance of the difference of score change between responders and non-responders to DAS28 changes under treatment. In addition, we examined whether the FOIAS was correlated with clinical outcome and ultrasound data by use of Spearman's correlation coefficients including the analysis assessing specific points of time and the change between two points of time. The significance level of 0.05 (5\%) was used. $p$ values were not adjusted for multiple testing due to the explorative character of the analyses. Statistical analyses were performed with the statistical program $R$ [35]. If not specified otherwise, the descriptive statistics provided median values (1. quartile; 3 . quartile).

\section{Results}

Patients' characteristics are presented in Table 1. Our analyses focused on the 35 of 42 patients who completed the study after 12 months.

\section{Clinical parameters}

During 12 months follow-up, we found statistically significant reductions in TJC $7.0(3.5 ; 15)$ to $1.0(0 ; 3)$ and SJC $5.0(3 ; 9.5)$ to $1.0(0 ; 2)$, respectively (each $p<0.001$; see Table 2).

At baseline, patients had high disease activity with median DAS28(ESR) of 5.61 (4.8;6.23). After 1 year, disease activity was statistically significantly reduced to a median DAS28 of $3.31(2.45 ; 3.98)(p<0.001)$ which corresponds to moderate disease activity (see Table 2 ). By the end of the study, $31.4 \%(11 / 35)$ of patients had achieved remission $(\mathrm{DAS} 28<2.6)$.

\section{Fluorescence optical imaging (FOI)}

Statistically significant reductions were detected in the FOI sum score (FOIAS) in phase 1 from baseline (5.0, $(1.04 ; 26))$ to 12 months follow-up $(1.0(0 ; 4))$ in the total patient cohort $(p=0.0045)$. There were no statistically significant changes in the FOI sum score in phase 2, phase 3 , or PVM in the total cohort (see Table 3 and Fig. 1 and Additional file 1: Table S2 (analysis without DIP).

\section{Correlation of FOI and clinical parameters}

Regarding baseline data, no significant positive correlation between FOI and clinical parameters (TJC, SJC, and DAS28(ESR)) can be shown (see Fig. 2a).

FOI in phase 1 showed no statistically significant correlations with clinical data concerning the analysis of clinically affected joints and FOI after 12 months follow-up (see Fig. 2b). FOI phases 2 and 3 demonstrated weak to moderate correlations with DAS28(ESR) and SJC. PVM correlated significantly with all three clinical parameters. While the correlation with TJC was only weak $(r=0.38)$, PVM correlated moderately with SJC and DAS28(ESR) $(r=0.58$, 
Table 1 Patients' characteristics at baseline

\begin{tabular}{|c|c|c|}
\hline & & Summary statistics \\
\hline \multirow[t]{2}{*}{ Age $(n=35)$} & At the beginning of the study & $\begin{array}{l}53.32(13.63) \\
(22.23 ; 74)\end{array}$ \\
\hline & Number of patients $\geq 65$ years (LORA) & 8/35 (22.86\%) \\
\hline Gender $(n=35)$ & Female & 24/35 (68.57\%) \\
\hline \multirow[t]{2}{*}{ Disease duration $(n=35)$} & $\begin{array}{l}\text { Duration from initial diagnosis until inclusion } \\
\text { in the study (in months) }\end{array}$ & $\begin{array}{l}0.2(0.42) \\
(0 ; 1.98)\end{array}$ \\
\hline & Duration of symptoms (in months) & $\begin{array}{l}1.3(1.25) \\
(0.13 ; 4.5)\end{array}$ \\
\hline \multirow[t]{2}{*}{ Disease Activity Score 28 (DAS28) } & DAS28(ESR) $(n=34)$ & $\begin{array}{l}5.55(1.11) \\
(3.55 ; 7.57)\end{array}$ \\
\hline & DAS28(CRP) $(n=31)$ & $\begin{array}{l}5.02(1.12) \\
(3.09 ; 6.77)\end{array}$ \\
\hline \multirow[t]{2}{*}{ Laboratory parameters } & $\operatorname{ESR}(1 \mathrm{~h} / \mathrm{mm})(n=34)$ & $\begin{array}{l}39.62(22.23) \\
(8 ; 95)\end{array}$ \\
\hline & $\operatorname{CRP}(n<5.0 \mathrm{mg} / \mathrm{l})(n=32)$ & $\begin{array}{l}16.34(17.89) \\
(0 ; 66.52)\end{array}$ \\
\hline \multirow[t]{2}{*}{ Clinical examination $(n=35)$} & Swollen joint count (28-SJC) & $\begin{array}{l}6.31(4.73) \\
(1 ; 20)\end{array}$ \\
\hline & Tender joint count (28-TJC) & $\begin{array}{l}10.26(7.85) \\
(1 ; 25)\end{array}$ \\
\hline \multirow[t]{2}{*}{ VAS $(0-100 \mathrm{~mm})$ for disease activity } & Patient $(n=35)$ & $\begin{array}{l}58.14(18.79) \\
(20 ; 100)\end{array}$ \\
\hline & Physician $(n=21)$ & $\begin{array}{l}54.52(16.58) \\
(30 ; 90)\end{array}$ \\
\hline \multirow[t]{3}{*}{ Rheumatoid factor (RF) } & Seropositive $(n=34)$ & 15/35 (42.86\%) \\
\hline & Rheumatoid factor $\lg \mathrm{A}(n=29)$ & $\begin{array}{l}93.23(166.03) \\
(0.1 ; 500)\end{array}$ \\
\hline & Rheumatoid factor IgM $(n=31)$ & $\begin{array}{l}59.64(113.93) \\
(0.1 ; 500)\end{array}$ \\
\hline \multirow[t]{3}{*}{$\begin{array}{l}\text { Anti-citrullinated peptide } \\
\text { antibodies (ACPA) }(n=35)\end{array}$} & Level & $\begin{array}{l}250.34(393.27) \\
(0.42 ; 1000)\end{array}$ \\
\hline & Positive & 4/35 (11.43\%) \\
\hline & Highly positive & $15 / 35(42.86 \%)$ \\
\hline
\end{tabular}

Patients' characteristics at baseline: mean (SD); (min; max) or $n$ (\%); DAS28 Disease Activity Score of 28 joints, ESR erythrocyte sedimentation rate, CRP C-reactive protein

$r=0.51$, see Fig. $2 \mathrm{~b})$. The corresponding $p$ values of the correlation coefficients were $<0.05$. An additional statistical analysis performed without the DIP joints in FOI did not change the level or direction of correlation (for further data see Additional file 1: Tables S3a-b).

\section{Correlations between FOI and US}

US data of baseline and after 12 months are presented in Table 2.

With respect to the calculated correlations in the total group, tenosynovitis in greyscale ultrasound (GSUS) and PDUS correlated with every phase and PVM at baseline, but strongest for PD-tenosynovitis with phase $2(r=0.73$; $p<0.05)$. With regard to GS- and PD-synovitis, significant positive correlations with phase 1, phase 2, and PVM at baseline can be shown. While GS-synovitis most strongly correlated with PVM in FOI $(r=0.6)$, the strongest correlation between PD-synovitis and FOI was demonstrated for phase $1(r=0.59)$ (Fig. 3a).

After 12 months, FOI in phase 2 demonstrated the strongest correlations, especially with PD-tenosynovitis $(r=0.63$; $p<0.05)$ and GS-tenosynovitis $(r=0.59 ; p<0.05)$. For phase 1 , low correlation with GS-synovitis can be demonstrated $(r=0.48, p<0.05)$. However, PVM was the only FOI part correlating with all considered US parameters (Fig. 3b).

\section{Comparison of clinical findings and $\mathrm{FOI}$ in responders vs. non-responders}

According to the EULAR response criteria [32], $n=16$ (45.7\%) patients were defined as responders (DAS28(ESR) $\leq 3.2$ and improvement of $>0.6)$ and $n=19(54.3 \%)$ as non-responders (DAS28(ESR) $>3.2$ ). 
Table 2 Clinical and ultrasound parameters at baseline and after 12 months in total population, group of responders and nonresponders

\begin{tabular}{|c|c|c|c|c|}
\hline & $\begin{array}{l}\text { Month of visit } \\
0(\mathrm{~V} 0)^{*}\end{array}$ & $\begin{array}{l}\text { Month of visit } \\
12(\mathrm{~V} 12)^{*}\end{array}$ & $\begin{array}{l}\text { Difference between } \\
\text { V12 and } \mathrm{V}^{*}\end{array}$ & $\begin{array}{l}p \text { value (Wilcoxon } \\
\text { signed rank test) }\end{array}$ \\
\hline \multicolumn{5}{|c|}{ Total population ( $n=35$ for clinical, $n=34$ for US7 parameters) } \\
\hline $28-S J C$ & $\begin{array}{l}5(3 ; 9.5) \\
(1 ; 20)\end{array}$ & $\begin{array}{l}1(0 ; 2) \\
(0 ; 10)\end{array}$ & $\begin{array}{l}-4(-7 ;-1) \\
(-19 ; 3)\end{array}$ & $<0.001$ (sig.) \\
\hline 28-TJC & $\begin{array}{l}7(3.5 ; 15) \\
(1 ; 25)\end{array}$ & $\begin{array}{l}1(0 ; 3) \\
(0 ; 26)\end{array}$ & $\begin{array}{l}-4(-10 ;-1) \\
(-24 ; 6)\end{array}$ & $<0.001$ (sig.) \\
\hline DAS28(ESR) & $\begin{array}{l}5.61(4.8 ; 6.23) \\
(3.55 ; 7.57)\end{array}$ & $\begin{array}{l}3.31(2.45 ; 3.98) \\
(1.13 ; 6.19)\end{array}$ & $\begin{array}{l}-2.22(-3.11 ;-1.39) \\
(-5.45 ; 0.56)\end{array}$ & $<0.001$ (sig.) \\
\hline GS-synovitis & $\begin{array}{l}7(5.5 ; 9.5) \\
(2 ; 15)\end{array}$ & $\begin{array}{l}6(4.25 ; 7) \\
(2 ; 10)\end{array}$ & $\begin{array}{l}-1(-3 ; 0) \\
(-9 ; 7)\end{array}$ & 0.0112 (sig.) \\
\hline GS-tenosynovitis & $\begin{array}{l}3(2 ; 4) \\
(0 ; 5)\end{array}$ & $\begin{array}{l}2.5(2 ; 3) \\
(0 ; 4)\end{array}$ & $\begin{array}{l}-0.5(-1.75 ; 0) \\
(-4 ; 2)\end{array}$ & 0.0239 (sig.) \\
\hline PD-synovitis & $\begin{array}{l}4(3 ; 7) \\
(2 ; 15)\end{array}$ & $\begin{array}{l}3(2 ; 3.75) \\
(0 ; 11)\end{array}$ & $\begin{array}{l}-1(-3 ; 0) \\
(-9 ; 1)\end{array}$ & 0.00004 (sig.) \\
\hline PD-tenosynovitis & $\begin{array}{l}3(2 ; 4) \\
(0 ; 7)\end{array}$ & $\begin{array}{l}2(1.25 ; 3) \\
(0 ; 5)\end{array}$ & $\begin{array}{l}0(-2 ; 0.75) \\
(-4 ; 1)\end{array}$ & 0.0163 (sig.) \\
\hline \multicolumn{5}{|c|}{ Group of responders $(n=16)$} \\
\hline $28-S J C$ & $\begin{array}{l}3.5(1.75 ; 8.25) \\
(1 ; 15)\end{array}$ & $\begin{array}{l}0(0 ; 1) \\
(0 ; 3)\end{array}$ & $-3.5(-8.25 ;-1)(-14 ; 1)$ & 0.002 (sig.) \\
\hline 28-TJC & $\begin{array}{l}4.5(3 ; 10.5) \\
(1 ; 24)\end{array}$ & $\begin{array}{l}0(0 ; 0.25) \\
(0 ; 2)\end{array}$ & $-3.5(-10.5 ;-3)(-24 ;-1)$ & $<0.001$ (sig.) \\
\hline DAS28(ESR) & $\begin{array}{l}4.88(4.33 ; 6.18) \\
(3.55 ; 7.33)\end{array}$ & $\begin{array}{l}2.38(1.89 ; 2.68) \\
(1.13 ; 3.18)\end{array}$ & $\begin{array}{l}-2.82(-3.82 ;-1.82) \\
(-5.45 ;-1.14)\end{array}$ & $<0.001$ (sig.) \\
\hline GS-synovitis & $\begin{array}{l}8(6 ; 9.25) \\
(2 ; 12)\end{array}$ & $\begin{array}{l}6(4 ; 7) \\
(3 ; 9)\end{array}$ & $\begin{array}{l}-2(-4.25 ; 0) \\
(-9 ; 7)\end{array}$ & 0.038 (sig.) \\
\hline GS-tenosynovitis & $\begin{array}{l}4(2.75 ; 5) \\
(1 ; 5)\end{array}$ & $\begin{array}{l}2.5(2 ; 3) \\
(1 ; 4)\end{array}$ & $\begin{array}{l}-1(-2 ; 0) \\
(-4 ; 2)\end{array}$ & 0.0274 (sig.) \\
\hline PD-synovitis & $\begin{array}{l}4(3.75 ; 6.5) \\
(2 ; 11)\end{array}$ & $\begin{array}{l}3(2 ; 3) \\
(1 ; 4)\end{array}$ & $\begin{array}{l}-2(-5 ;-0.75) \\
(-8 ; 1)\end{array}$ & 0.0028 (sig.) \\
\hline PD-tenosynovitis & $\begin{array}{l}3(2 ; 5) \\
(1 ; 7)\end{array}$ & $\begin{array}{l}2(2 ; 3) \\
(1 ; 3)\end{array}$ & $\begin{array}{l}-1(-2.25 ; 0) \\
(-4 ; 1)\end{array}$ & 0.01 (sig.) \\
\hline \multicolumn{5}{|c|}{ Group of non-responders ( $n=19$ for clinical, $n=18$ for US7 parameters) } \\
\hline $28-5 J C$ & $\begin{array}{l}6(3.5 ; 9.5) \\
(1 ; 20)\end{array}$ & $\begin{array}{l}1(0 ; 4) \\
(0 ; 10)\end{array}$ & $\begin{array}{l}-5(-6.5 ;-2) \\
(-19 ; 3)\end{array}$ & 0.001 (sig.) \\
\hline 28-TJC & $\begin{array}{l}11(5.5 ; 18.5) \\
(1 ; 25)\end{array}$ & $\begin{array}{l}3(1.5 ; 11) \\
(0 ; 26)\end{array}$ & $\begin{array}{l}-4(-8 ; 0.5) \\
(-22 ; 6)\end{array}$ & 0.01 (sig.) \\
\hline DAS28(ESR) & $\begin{array}{l}5.82(5.34 ; 6.23) \\
(3.61 ; 7.57)\end{array}$ & $\begin{array}{l}3.95(3.51 ; 5.21) \\
(3.28 ; 6.19)\end{array}$ & $\begin{array}{l}-1.62(-2.61 ;-0.51) \\
(-3.73 ; 0.56)\end{array}$ & < 0.001 (sig.) \\
\hline GS-synovitis & $\begin{array}{l}7(4.5 ; 9.5) \\
(2 ; 15)\end{array}$ & $\begin{array}{l}6(5 ; 8.5) \\
(2 ; 10)\end{array}$ & $\begin{array}{l}-1(-2 ; 0.75) \\
(-5 ; 6)\end{array}$ & 0.1641 \\
\hline GS-tenosynovitis & $\begin{array}{l}2(2 ; 4) \\
(0 ; 5)\end{array}$ & $\begin{array}{l}2.5(1 ; 3) \\
(0 ; 4)\end{array}$ & $\begin{array}{l}0(-1 ; 1) \\
(-3 ; 2)\end{array}$ & 0.506 \\
\hline PD-synovitis & $\begin{array}{l}4(2.5 ; 7) \\
(2 ; 15)\end{array}$ & $\begin{array}{l}3(1 ; 5) \\
(0 ; 11)\end{array}$ & $\begin{array}{l}-1(-2 ; 0) \\
(-9 ; 1)\end{array}$ & 0.0058 (sig.) \\
\hline PD-tenosynovitis & $\begin{array}{l}2(1 ; 3) \\
(0 ; 7)\end{array}$ & $\begin{array}{l}2.5(1 ; 3) \\
(0 ; 5)\end{array}$ & $\begin{array}{l}0(-0.75 ; 1) \\
(-4 ; 1)\end{array}$ & 0.7732 \\
\hline
\end{tabular}

Clinical and ultrasound (US) parameters at baseline and after 12 months in total population, group of responders and non-responders: ${ }^{*}$ Median (1. quartile; 3. quartile); (min; max), significance level $=0.05 ; 28$-SJC swollen joint count of 28 joints, 28-TJC tender joint count of 28 joints, DAS28(ESR) Disease Activity Score of 28 joints and erythrocyte sedimentation rate (ESR), GS greyscale mode in ultrasound, PD Power Doppler mode in ultrasound

Regarding the responders (DAS28(ESR) $\leq 3.2$ and improvement of $>0.6 ; n=16)$ and non-responders (DAS28(ESR) $>3.2 ; n=19$ ), both groups demonstrated a statistically significant decline in affected tender and swollen joints after 12 months. Non-responders had a greater number of tender (11 (5.5;18.5)) and swollen (6; (3.5;9.5)) 
Table 3 FOIAS of phases $1-3$ and PVM (PrimaVistaMode) in FOI at baseline and after 12 months ( $n=35$ for FOIAS parameters

\begin{tabular}{lllll}
\hline & $\begin{array}{l}\text { Month of visit } \\
0(\mathrm{~V} 0)^{*}\end{array}$ & $\begin{array}{l}\text { Month of visit } \\
12(\mathrm{~V} 12)^{*}\end{array}$ & $\begin{array}{l}\text { Difference between } \\
\text { V12 and V0* }\end{array}$ & $\begin{array}{l}p \text { value (Wilcoxon } \\
\text { signed rank test) }\end{array}$ \\
\hline Phase 1 & $5(1.04 ; 26)$ & $1(0 ; 4)$ & $-3(-17 ; 0)$ & 0.00445 (sig.) \\
& $(0 ; 70.91)$ & $(0 ; 32)$ & $(-69.91 ; 12)$ & 0.6004 \\
Phase 2 & $16(10.5 ; 25)$ & $16(9.5 ; 24)$ & $(-18 ; 18)$ & 0.5451 \\
& $(1 ; 40)$ & $(2 ; 43)$ & $0(-1 ; 1.5)$ & $(-12 ; 9)$ \\
Phase 3 & $1(0 ; 2.5)$ & $(0 ; 10)$ & $-1(-4 ; 4)$ & $(-15 ; 14)$ \\
PVM & $(0 ; 15)$ & $9(3.5 ; 14)$ & $(0 ; 26)$ & 0.7461
\end{tabular}

Phases 1-3 and PVM (PrimaVistaMode) of FOI at baseline and after 12 months $(n=35)$ : FOIAS fluorescence optical imaging activity score; *median (1. quartile; 3. quartile); (min; max); significance level $=0.05$

joints at baseline than the group of responders (TJC: 4.5 (3; $10.5)$ and SJC: $3.5(1.75 ; 8.25)$, respectively). After 12 months, the number of tender and swollen joints decreased to 0 in responders (see Table 2). In non-responders, the median number of tender joints and swollen joints was 3 $(1.5 ; 11)$ and $1(0 ; 4)$, respectively (see Table 2$)$.

With regard to US7 score parameters, the group of responders showed significant decrease in all US7 parameters, while the group of non-responders revealed significant decrease only in PD-synovitis.
We found no statistically significant difference in the change of the FOI sum score between responders and non-responders for the FOI phases 2 and 3 and PVM relating to EULAR response criteria [32-34] for low disease activity. In FOI phase 1 , the difference in the change of FOI sum score was similar in non-responders $(p=0.047)$ and responders $(p=0.052)$ (see Fig. 4a). There were no statistically significant differences across patients who did vs. did not achieve remission for FOI phases 2 and 3 and PVM. For FOI phase 1, statistically
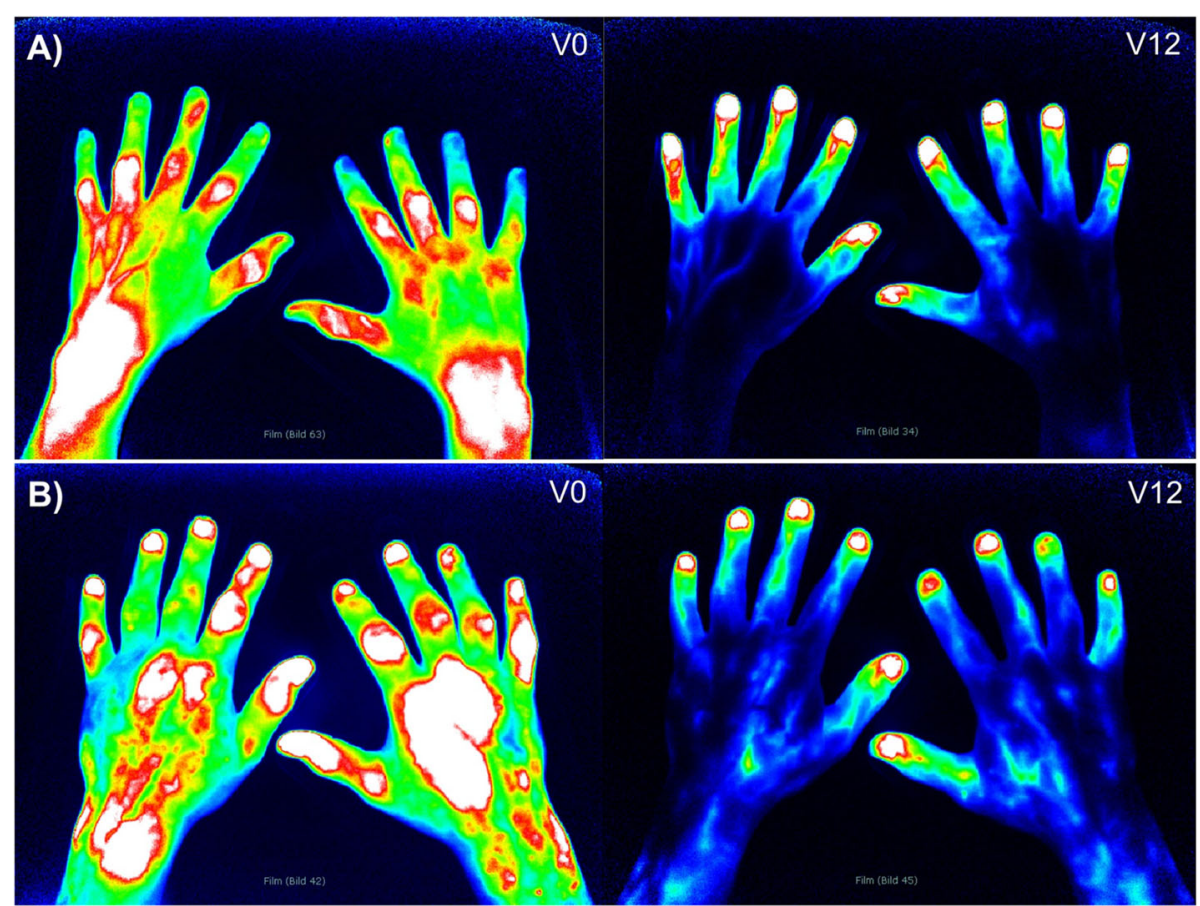

Fig. 1 Reduction of early enhancement in FOI (fluorescence optical imaging) phase 1 after 12 months follow-up: a V0: Example with early high enhancement in phase 1 before ICG flooding in the fingertips, especially in the wrists, PIPs, and IPs of both hands. Moderate enhancement in MCP II and IV of the right hand. V12: High physiological enhancement in the fingertips in phase 1 after 12 months. No enhancement in the finger and hand joints. b Example of early enhancement in phase 1 in both hands, especially in MCP II and III of the right hand. High enhancement also in PIPs of both hands, left wrist, and MCP II and III. Physiological signal in the fingertips. V12: High physiological enhancement in the fingertips in phase 1 after 12 months. No significant enhancement in the finger and hand joints. V0: baseline, V12: follow-up after 12 months 


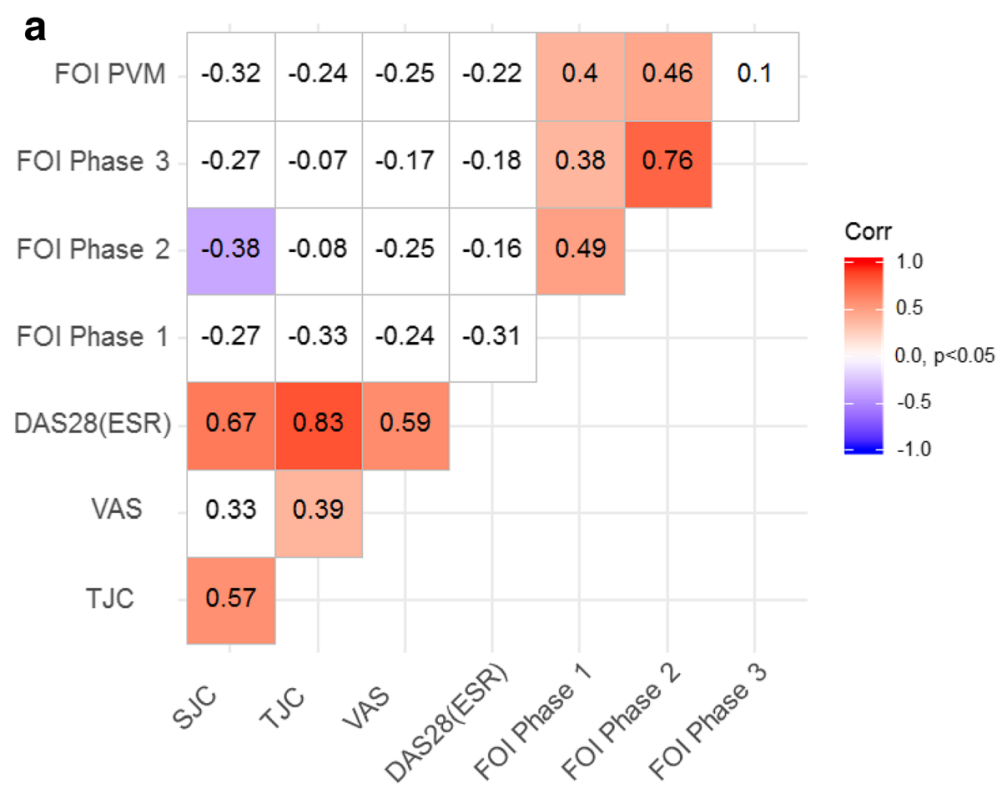

b

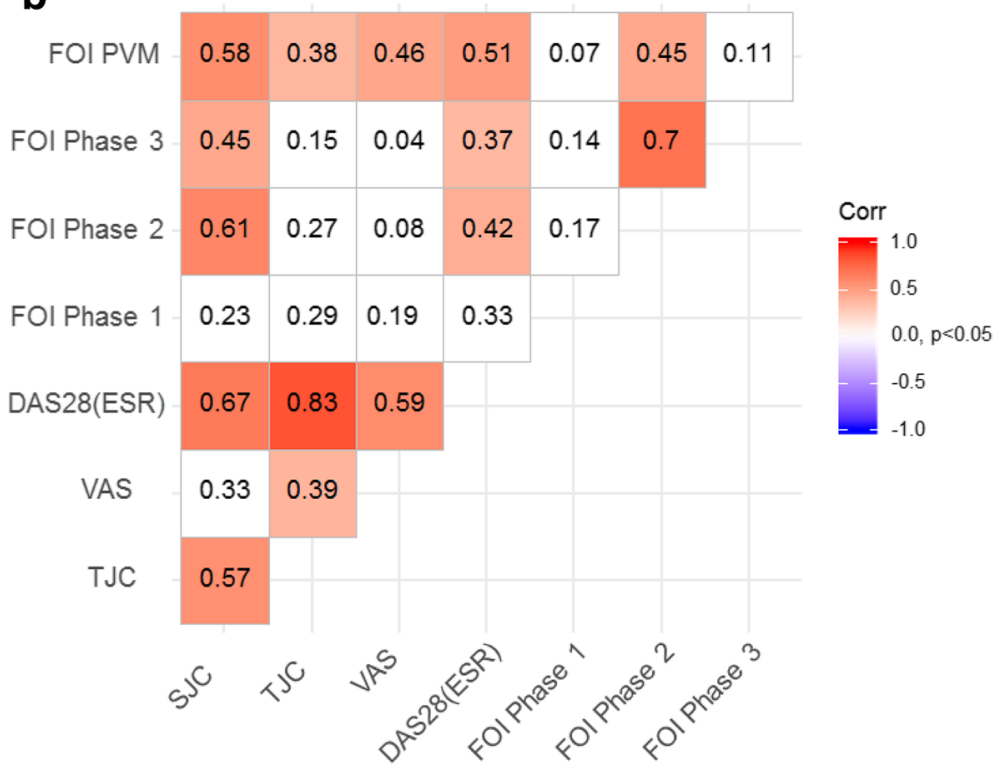

Fig. 2 Pairwise correlation between the number of affected joints in clinical examination and FOI phases 1, 2, and 3 and PVM: significance level = 0.05; FOI = fluorescence optical imaging; PVM = PrimaVistaMode; $\mathrm{SJC}=$ swollen joint count; TJC = tender joint count; DAS28(ESR) = Disease Activity Score of 28 joints and erythrocyte sedimentation rate (ESR); VAS = visual analog scale. Spearman's correlation coefficients and $p$ values are presented. a measurement at V0 (baseline) b change at V12 (12 months follow-up)

significant difference was shown only in responders regarding clinical remission status (see Fig. 4b).

\section{Discussion}

To our knowledge, this present study is the first one describing the changes of FOI in a homogeneous cohort of patients with early and active RA over a period of 12 months under antirheumatic therapy.

Regarding clinical and laboratory disease activity, DAS28 decreased from high disease activity (DAS28 =
$5.61)$ to moderate (DAS28 $=3.31)$ over the time period described. $31.4 \%$ of patients $(n=16)$ achieved remission of DAS28 $<2.6$ under antirheumatic therapy.

Concerning FOI, we found significant reductions in the FOI sum score in phase 1 in the total cohort, whereas the other phases remained stable. These results are in line with previous results by Meier et al., who found a significant reduction in early signal intensity after 24 weeks of therapy using a computer-based evaluation of FOI [30]. In a study by Werner et al., phase 1 featured the highest 


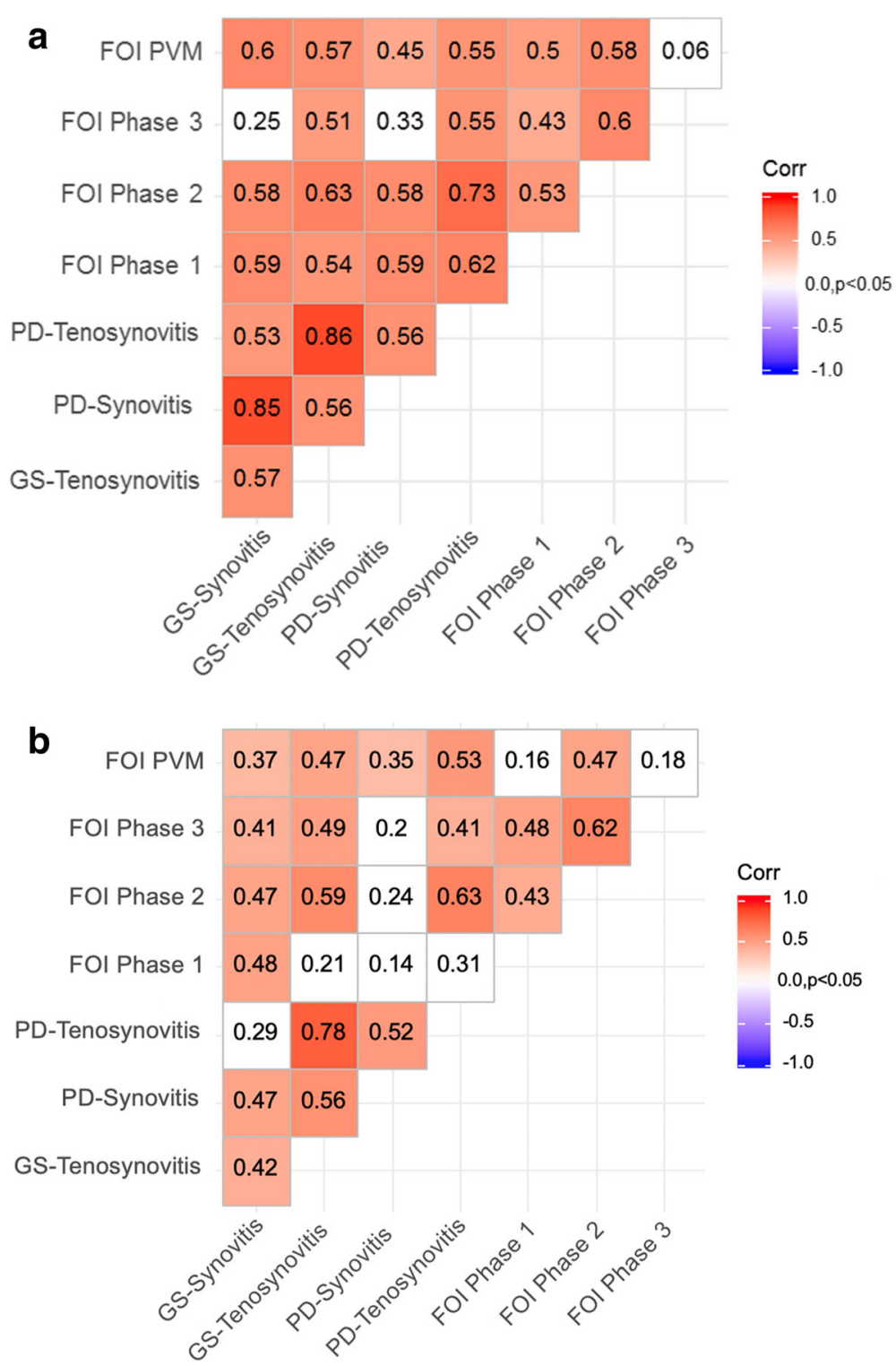

Fig. 3 Pairwise correlation between US7 and FOI phase 1, 2, and 3 and PVM: significance level =0.05; FOI = fluorescence optical imaging; PVM= PrimaVistaMode; $\mathrm{PD}=$ power Doppler mode in ultrasound, GS = greyscale mode in ultrasound. Spearman's correlation coefficients and $p$ values are presented. a measurements at V0 (baseline) $\mathbf{b}$ change at V12 (12 months follow-up)

agreement between clinical examination and FOI. In addition, the highest specificity was calculated for phase 1 compared to MRI and US in this study [21], which was also confirmed by Krohn et al. [24]. Besides, phase 1 did not show any pathological changes in a healthy cohort, confirming the hypothesis that this early phase reflects active inflammation with increased vascularization and therefore high clinical disease activity [21]. In a previous study, we examined FOI in patients with either osteoarthritis (OA) or RA. OA patients showed significantly less activity in phase 1 (maximum degree 1), but a consistently high signal accumulation in phase 2 (especially in the wrist) [26]. These results support the hypothesis that phase 1 detects an active inflammation [21, 22] since OA is usually characterized by a less pronounced inflammation as compared to systemic inflammatory joint diseases.

In our analysis, we did not find a significant correlation between the change of phase 1 and joint count. The lack of correlations between phase 1 and clinical parameters may be due to different parameters we assess in clinical examination and FOI. While we investigate a disturbed microcirculation in FOI, we document morphological changes in swollen fingers as a result of infiltrated cells in the synovial membrane and pannus. The impaired microcirculation visualized by FOI comprises neoangiogenesis, hyperperfusion, and capillary leakage 

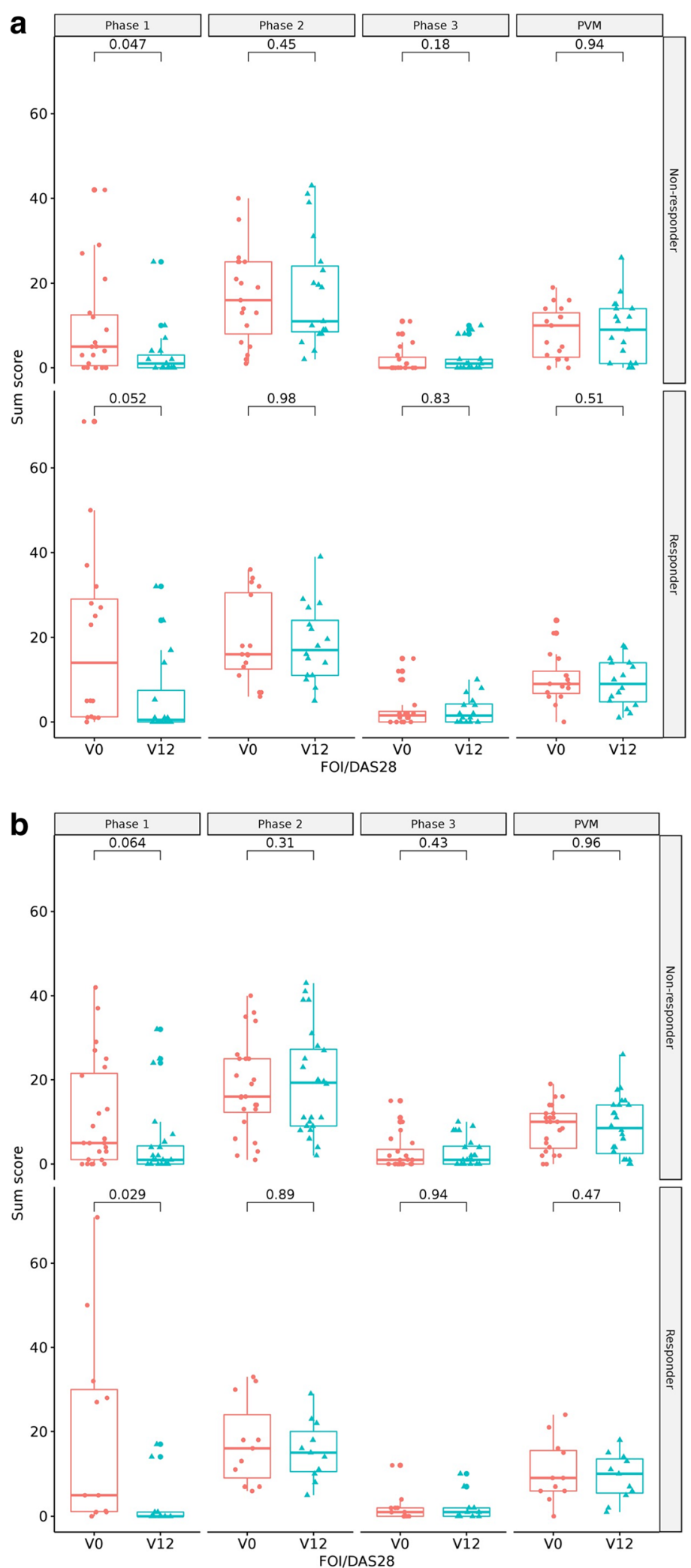

Fig. 4 (See legend on next page.) 
(See figure on previous page.)

Fig. 4 a Course of FOI sum scores in comparison to EULAR response criteria of "low disease activity" according to DAS28. b Course of FOI sum scores in comparison to EULAR response criteria of "remission" according to DAS28: non-responder (DAS28(ESR) > 3.2), responder (DAS28(ESR) $\leq 3.2$ and improvement of > 0.6). FOI = fluorescence optical imaging; DAS28 = Disease Activity Score of 28 joints. V0 (red): baseline, V12 (blue): follow-up after 12 months

within the inflammatory process of RA [36]. It may be assumed that both pathologies (microcirculation and morphological changes) within the articular region appear on different time points in the disease course. On the other hand, neoangiogenesis is an important component in the formation of pannus and, therefore, not only found around the inflamed joint [36]. Another explanation for the lack of correlation may be false-positive findings of FOI. However, Werner et al. demonstrated a low rate of false-positive findings between 0.5 and $5 \%$ by FOI [22]. Thus, our results stand in contrast to the results by Werner et al. who presented good agreement rates and low, but significant, correlations between FOI and clinical examination. It should be noted that FOI detects any inflammation including scratches, plaques, and insect bites. On this account, the evaluation requires a well-trained investigator [22]. However, the localization, form, and temporal distribution of enhancement in the individual FOI phases allow a differentiation [22] and may indicate the underlying pathology or possible disease [26].

In addition, Werner et al. suggested divergence between local inflammation in the hand and systemic inflammation [21]. Furthermore, high variance for components of the DAS28 was recently described [37], while FOI is a more objective technical tool.

After 1 year under csDMARD or bDMARD therapy, approximately $46 \%$ of the patients in our study achieved a clinical response stage according to the EULAR response criteria [32-34] and showed a reduction in disease activity according to the treat-to-target principle (T2T). The change in FOI sum scores was similar in patients with and without a clinical response. The significant reductions in phase 1 also in non-responders probably show a more objective reduction of inflammation by FOI, while the clinical non-response can also depend on individual person-related (i.e., psychological) factors which may lead to elevated global disease activity on VAS. Recently, Hammer et al. showed no association between tender joints and synovitis in GSUS and PDUS, while a strong correlation between swollen joints and US synovitis was calculated. In addition, they found a primary associationn between tender joints and patient-reported joint pain [38]. These findings support that the parameters of DAS28 hardly correlated with the sum scores of FOI also in this present study. Similar results for FOI were published by Werner et al. assuming different characteristics of pathologies [21].

We conducted correlation analyses between musculoskeletal ultrasound and FOI findings. At baseline examination, strong correlations were found between all FOI phases and the ultrasound parameters, especially tenosynovitis in PDUS. The strongest correlations were found for FOI phase 2 at both baseline and after 12 months of therapy. In contrast, phase 1 did only show a positive correlation with synovitis in GSUS after 12 months follow-up. The meaning of phase 2 as a marker of subclinical activity has already been discussed in previous studies [21, 22, 24]; however, no longitudinal data exist yet showing a predictive value of phase 2, for example in terms of erosive disease or flare prediction. The strong signal accumulation could be caused by increased vascularization due to chronic inflammation. The low correlations of phase 1 with US at month 12 may indicate that there was no or only a small amount of acute inflammation after 1 year of intensive therapy, whereas the greyscale US synovitis findings can persist. FOI phase 1 is probably a reflection of acute inflammation. A good response of early enhancement in FOI to therapeutic interventions demonstrated by Meier et al. showed a decrease of early signal intensity after 6 months in response to therapy [30].

\section{Conclusions}

In conclusion, activity in FOI phase 1 changed significantly over 1 year under therapy in the group of responders regarding the parameter of clinical remission (DAS28). However, a significant change of FOI phase 1 was also observed in non-responders, so we cannot objectively deduce a therapy response of phase 1 . However, the correlation of FOI with ultrasound as a validated and well-established imaging technique in daily rheumatological practice should be emphasized. In the issue, the role of FOI in therapy monitoring needs to be investigated in further studies.

\section{Supplementary information}

Supplementary information accompanies this paper at https://doi.org/10. 1186/s13075-019-1989-5.

Additional file 1. The supplementary material gives further information on methods including patient consent, EULAR response criteria and ultrasound. It reveals additional results of FOIAS in phases 1-3 and PVM (PrimaVistaMode) of FOl at baseline and after 12 months as well as correlation to number of clinically affected joints with DIP joint excluded in the analyses. (DOCX 39 kb)

\section{Abbreviations}

ACPA: Anti-citrullinated peptide antibodies; bDMARDs: Biologic diseasemodifying antirheumatic drugs; BMBF: Federal Ministry of Education and Research (Bundesministerium für Bildung und Forschung); 
CSDMARDs: Conventional synthetic disease-modifying antirheumatic drugs; CRP: C-reactive protein; DAS28: Disease Activity Score of 28 joints; DIP: Distal interphalangeal joints; ESR: Erythrocyte sedimentation rate; EULAR: European League Against Rheumatism; FOI : Fluorescence optical imaging;

FOIAS: Fluorescence optical imaging activity score; GSUS: Greyscale ultrasound; ICG: Indocyanine green; IP: Interphalangeal joint of the thumb; MCP: Metacarpophalangeal joints; MRI: Magnetic resonance imaging; OA: Osteoarthritis; PDUS: Power Doppler mode, power Doppler ultrasound; PIP: Proximal interphalangeal joints; PVM: PrimaVistaMode; p1: Phase 1 in FOl; p2: Phase 2 in FOl; p3: Phase 3 in FOl; RA: Rheumatoid arthritis; RF: Rheumatoid factor; SJC: Swollen joint count; TJC: Tender joint count; T2T: Treat-to-target principle; US: Musculoskeletal ultrasound, ultrasonography; VAS: Visual analog scale; V0: Baseline visit; V12: Visit after 12 months

\section{Acknowledgements}

We would like to acknowledge the study nurses Gabriela Schmittat and Silvia Pade for logistical and technical assistance. In this paper, a part of the results of the dissertation of LIS "The role of fluorescence-optical imaging Xiralite $^{\circledast}$ in therapy monitoring of patients with early, active rheumatoid arthritis - in comparison to clinical parameters and musculoskeletal ultrasound", submitted in 2018 to the Charité-Universitätsmedizin, Berlin, Germany, is presented.

\section{Authors' contributions}

AMG, LIS, TH, MB, and SO contributed substantially to the conception and design of the study. AMG, LIS, IKH, UM, LL, GRB, and SO made substantial contributions to acquisition, analysis, and interpretation of data. LL performed the statistical analyses. AMG, LIS, LL, and SO drafted the paper. AMG, LIS, IKH, SH, TH, PH, GRB, MB, LL, and SO revised the article for important intellectual content. All authors gave final approval of the version to be published and agreed to be accountable for all aspects of the work in ensuring that questions related to the accuracy or integrity of any part of the work are appropriately investigated and resolved.

\section{Funding}

The study was supported by the BMBF (German ministry for education and research) funded project "ArthroMark" subproject No.7.

The funding sources had no role in the design and conduct of the study; collection, management, analysis, and interpretation of the data; preparation, review, or approval of the manuscript; or decision to submit the manuscript for publication.

\section{Availability of data and materials}

The datasets used and/or analyzed during the current study are available from the corresponding author on reasonable request.

\section{Ethics approval and consent to participate}

The study was approved by the local Medical Ethical Committee of the Charité - Universitätsmedizin, Berlin, Germany. All patients provided informed consent to participate in the study.

\section{Consent for publication}

All patients provided informed consent to publish the data.

\section{Competing interests}

The authors declare that they have no competing interests.

\author{
Author details \\ 'Department of Rheumatology and Clinical Immunology, \\ Charité-Universitätsmedizin Berlin, Charitéplatz 1, 10117 Berlin, Germany. \\ ${ }^{2}$ Department of Rheumatology, Diakonhjemmet Hospital, Oslo, Norway. \\ ${ }^{3}$ Institut für medizinische Informationsverarbeitung, Biometrie und \\ Epidemiologie (IBE), Ludwig-Maximilians-Universität München, Munich, \\ Germany. ${ }^{4}$ Innere Medizin - Bereich Rheumatologie und Klinische \\ Immunologie, Park-Klinik Weißensee, Berlin, Germany.
}

Received: 12 June 2019 Accepted: 4 September 2019 Published online: 18 September 2019

\section{References}

1. Prevoo ML, Van't Hof MA, Kuper HH, van Leeuwen MA, van de Putte LB, van Riel PL. Modified disease activity scores that include twenty-eight-joint counts. Development and validation in a prospective longitudinal study of patients with rheumatoid arthritis. Arthritis Rheum. 1995;38(1):44-8.

2. Colebatch AN, Edwards CJ, Ostergaard M, van der Heijde D, Balint PV, D'Agostino MA, et al. EULAR recommendations for the use of imaging of the joints in the clinical management of rheumatoid arthritis. Ann Rheum Dis. 2013;72(6):804-14.

3. Joshua F, Lassere M, Bruyn GA, Szkudlarek M, Naredo E, Schmidt WA, et al, Summary findings of a systematic review of the ultrasound assessment of synovitis. J Rheumatol. 2007;34(4):839-47.

4. Backhaus M, Kamradt T, Sandrock D, Loreck D, Fritz J, Wolf KJ, et al. Arthritis of the finger joints: a comprehensive approach comparing conventional radiography, scintigraphy, ultrasound, and contrast-enhanced magnetic resonance imaging. Arthritis Rheum. 1999;42(6):1232-45.

5. Wakefield RJ, Gibbon WW, Conaghan PG, O'Connor P, McGonagle D, Pease $C$, et al. The value of sonography in the detection of bone erosions in patients with rheumatoid arthritis: a comparison with conventional radiography. Arthritis Rheum. 2000;43(12):2762-70.

6. Szkudlarek M, Court-Payen M, Jacobsen S, Klarlund M, Thomsen HS, Ostergaard M. Interobserver agreement in ultrasonography of the finger and toe joints in rheumatoid arthritis. Arthritis Rheum. 2003;48(4):955-62.

7. Scheel AK, Hermann KG, Ohrndorf S, Werner C, Schirmer C, Detert J, et al. Prospective 7 year follow up imaging study comparing radiography, ultrasonography, and magnetic resonance imaging in rheumatoid arthritis finger joints. Ann Rheum Dis. 2006;65(5):595-600.

8. Ohrndorf S, Backhaus M. Advances in sonographic scoring of rheumatoid arthritis. Ann Rheum Dis. 2013;72(Suppl 2):ii69-75.

9. Haavardsholm EA, Ostergaard M, Hammer HB, Boyesen P, Boonen A, van der Heijde D, et al. Monitoring anti-TNFalpha treatment in rheumatoid arthritis: responsiveness of magnetic resonance imaging and ultrasonography of the dominant wrist joint compared with conventional measures of disease activity and structural damage. Ann Rheum Dis. 2009, 68(10):1572-9.

10. Keen HI, Mease PJ, Bingham CO 3rd, Giles JT, Kaeley G, Conaghan PG. Systematic review of MRI, ultrasound, and scintigraphy as outcome measures for structural pathology in interventional therapeutic studies of knee arthritis: focus on responsiveness. J Rheumatol. 2011;38(1):142-54.

11. Beals C, Baumgartner R, Peterfy C, Balanescu A, Mirea G, Harabagiu A, et al. Magnetic resonance imaging of the hand and wrist in a randomized, doubleblind, multicenter, placebo-controlled trial of infliximab for rheumatoid arthritis: comparison of dynamic contrast enhanced assessments with semi-quantitative scoring. PLoS One. 2017;12(12):e0187397.

12. Ostendorf B, Scherer A, Backhaus M, Edelmann E, Kellner H, Schalm J, et al. Imaging techniques in rheumatology: magnetic resonance imaging in rheumatoid arthritis. Z Rheumatol. 2003;62(3):274-86.

13. Naredo E, Moller I, Cruz A, Carmona L, Garrido J. Power Doppler ultrasonographic monitoring of response to anti-tumor necrosis factor therapy in patients with rheumatoid arthritis. Arthritis Rheum. 2008;58(8):2248-56.

14. Ammitzboll-Danielsen M, Ostergaard M, Naredo E, lagnocco A, Moller I, D'Agostino MA, et al. The use of the OMERACT ultrasound tenosynovitis scoring system in multicenter clinical trials. J Rheumatol. 2018;45(2):165-9.

15. Kamishima T, Tanimura K, Shimizu M, Matsuhashi M, Fukae J, Kon Y, et al. Monitoring anti-interleukin 6 receptor antibody treatment for rheumatoid arthritis by quantitative magnetic resonance imaging of the hand and power Doppler ultrasonography of the finger. Skelet Radiol. 2011;40(6):745-55.

16. Nishino A, Kawashiri SY, Koga T, Iwamoto N, Ichinose K, Tamai M, et al. Ultrasonographic Efficacy of Biologic and Targeted Synthetic DiseaseModifying Antirheumatic Drug Therapy in Rheumatoid Arthritis From a Multicenter Rheumatoid Arthritis Ultrasound Prospective Cohort in Japan. Arthritis Care Res (Hoboken). 2018;70(12):1719-26.

17. Schmidt WA, Backhaus M, Sattler H, Kellner H, Kommission "Bildgebende Verfahren DGfR. [Imaging techniques in rheumatology: sonography in rheumatoid arthritis]. Z Rheumatol 2003;62(1):23-33.

18. Fischer T, Gemeinhardt I, Wagner S, Stieglitz DV, Schnorr J, Hermann KG, et al. Assessment of unspecific near-infrared dyes in laser-induced fluorescence imaging of experimental arthritis. Acad Radiol. 2006;13(1):4-13. 
19. Meier R, Krug C, Golovko D, Boddington S, Piontek G, Rudelius M, et al. Indocyanine green-enhanced imaging of antigen-induced arthritis with an integrated optical imaging/radiography system. Arthritis Rheum. 2010;62(8):2322-7.

20. Fischer T, Ebert B, Voigt J, Macdonald R, Schneider U, Thomas A, et al. Detection of rheumatoid arthritis using non-specific contrast enhanced fluorescence imaging. Acad Radiol. 2010;17(3):375-81.

21. Werner SG, Langer HE, Ohrndorf S, Bahner M, Schott P, Schwenke C, et al. Inflammation assessment in patients with arthritis using a novel in vivo fluorescence optical imaging technology. Ann Rheum Dis. 2012;71(4):504-10.

22. Werner SG, Langer HE, Schott P, Bahner M, Schwenke C, Lind-Albrecht G, et al. Indocyanine green-enhanced fluorescence optical imaging in patients with early and very early arthritis: a comparative study with magnetic resonance imaging. Arthritis Rheum. 2013;65(12):3036-44.

23. Schafer VS, Hartung W, Hoffstetter P, Berger J, Stroszczynski C, Muller M, et al. Quantitative assessment of synovitis in patients with rheumatoid arthritis using fluorescence optical imaging. Arthritis Res Ther. 2013;15(5):R124.

24. Krohn M, Ohrndorf S, Werner SG, Schicke B, Burmester GR, Hamm B, et al. Near-infrared fluorescence optical imaging in early rheumatoid arthritis: a comparison to magnetic resonance imaging and ultrasonography. J Rheumatol. 2015;42(7):1112-8.

25. Kisten $\mathrm{Y}$, Gyori N, Af Klint E, Rezaei H, Levitsky A, Karlsson A, et al. Detection of clinically manifest and silent synovitis in the hands and wrists by fluorescence optical imaging. RMD Open. 2015;1(1):e000106.

26. Glimm AM, Werner SG, Burmester GR, Backhaus M, Ohrndorf S. Analysis of distribution and severity of inflammation in patients with osteoarthitis compared to rheumatoid arthritis by ICG-enhanced fluorescence optical imaging and musculoskeletal ultrasound: a pilot study. Ann Rheum Dis. 2016;75(3):566-70.

27. Cherrick GR, Stein SW, Leevy CM, Davidson CS. Indocyanine green: observations on its physical properties, plasma decay, and hepatic extraction. J Clin Invest. 1960;39:592-600.

28. Alander JT, Kaartinen I, Laakso A, Patila T, Spillmann T, Tuchin W, et al. A review of indocyanine green fluorescent imaging in surgery. Int J Biomed Imaging. 2012;2012:940585.

29. Reinhart MB, Huntington CR, Blair $L$, Heniford $B T$, Augenstein VA. Indocyanine green: historical context, current applications, and future considerations. Surg Innov. 2016;23(2):166-75.

30. Meier R, Thuermel K, Noel PB, Moog P, Sievert M, Ahari C, et al. Synovitis in patients with early inflammatory arthritis monitored with quantitative analysis of dynamic contrast-enhanced optical imaging and MR imaging. Radiology. 2014;270(1):176-85.

31. Pages: https://www.arthromark.de/index.php. Access 3 July 2019.

32. van Gestel AM, Prevoo ML, Van't Hof MA, van Rijswijk MH, van de Putte $L B$, van Riel PL. Development and validation of the European League Against Rheumatism response criteria for rheumatoid arthritis. Comparison with the preliminary American College of Rheumatology and the World Health Organization/International League Against Rheumatism Criteria. Arthritis Rheum. 1996:39(1):34-40.

33. van Gestel AM, Haagsma CJ, van Riel PL. Validation of rheumatoid arthritis improvement criteria that include simplified joint counts. Arthritis Rheum. 1998;41(10):1845-50.

34. van Gestel AM, Anderson JJ, van Riel PL, Boers M, Haagsma CJ, Rich B, et al. $A C R$ and EULAR improvement criteria have comparable validity in rheumatoid arthritis trials. American College of Rheumatology European League of Associations for Rheumatology. J Rheumatol. 1999;26(3):705-11.

35. Team RC. R: a language and environment for statistical computing. Vienna: R Foundation for Statistical Computing; 2017.

36. Gompels LL, Lim NH, Vincent T, Paleolog EM. In vivo optical imaging in arthritis--an enlightening future? Rheumatology (Oxford). 2010;49(8):1436-46.

37. Siemons $\mathrm{L}$, ten Klooster PM, Vonkeman HE, van de Laar MA, Glas CA. Further optimization of the reliability of the 28-joint disease activity score in patients with early rheumatoid arthritis. PLoS One. 2014;9(6):e100544.

38. Hammer HB, Michelsen B, Sexton J, Haugen IK, Provan SA, Haavardsholm EA, Uhlig T, Kvien TK. Swollen, but not tender joints, are independently associated with ultrasound synovitis: results from a longitudinal observational study of patients with established rheumatoid arthritis. Ann Rheum Dis. 2019;78(9):1179-85.

\section{Publisher's Note}

Springer Nature remains neutral with regard to jurisdictional claims in published maps and institutional affiliations.

Ready to submit your research? Choose BMC and benefit from:

- fast, convenient online submission

- thorough peer review by experienced researchers in your field

- rapid publication on acceptance

- support for research data, including large and complex data types

- gold Open Access which fosters wider collaboration and increased citations

- maximum visibility for your research: over $100 \mathrm{M}$ website views per year

At BMC, research is always in progress.

Learn more biomedcentral.com/submissions 